\title{
Efficacy of sorafenib for the treatment of post-transplant hepatocellular carcinoma recurrence
}

\author{
Seong Hee Kang ${ }^{1,3, *}$, Hyeki Cho ${ }^{1, *}$, Eun Ju Cho ${ }^{1}$, Joon Yeul Nam ${ }^{1}$, Young Chang ${ }^{1}$, \\ Young Youn $\mathrm{Cho}^{1}$, Jeong-Hoon Lee ${ }^{1}$, Su Jong $\mathrm{Yu}^{1}$, Yoon Jun Kim${ }^{1}$, Nam-Joon $\mathrm{Yi}^{2}$, \\ Kwang-Woong Lee ${ }^{2}$, Kyung-Suk Suh ${ }^{2}$ and Jung-Hwan Yoon ${ }^{1}$ \\ ${ }^{1}$ Department of Internal Medicine and Liver Research Institute, Seoul National University College of Medicine, Seoul, Korea \\ ${ }^{2}$ Department of Surgery, Seoul National University College of Medicine, Seoul, Korea \\ ${ }^{3}$ Department of Internal Medicine, Yonsei University Wonju College of Medicine, Wonju, Korea \\ *These authors contributed equally to this work \\ Correspondence to: Eun Ju Cho, email: creatioex@gmail.com \\ Keywords: sorafenib; efficacy; liver transplantation; hepatocellular carcinoma; recurrence
}

Received: September 01,2017 Accepted: December 04, $2017 \quad$ Published: December 17, 2017

Copyright: Kang et al. This is an open-access article distributed under the terms of the Creative Commons Attribution License 3.0 (CC BY 3.0), which permits unrestricted use, distribution, and reproduction in any medium, provided the original author and source are credited.

\section{ABSTRACT}

The role of sorafenib in patients with hepatocellular carcinoma (HCC) recurrence after liver transplantation (LT) has been rarely studied. The aim of this study was to evaluate the efficacy of sorafenib in post-LT era. Consecutive patients with posttransplant HCC recurrence not eligible to resection or locoregional therapy were included. Patients receiving best supportive care (BSC) until 2007 were compared with those treated by sorafenib thereafter. Of a total of 65 patients, 20 patients received BSC and 45 received sorafenib. Clinical characteristics were similar between two groups except that sorafenib group received tacrolimus and mammalian targetof-rapamycin inhibitors more frequently than BSC group. Treatment with sorafenib conferred a survival advantage as compared with BSC for survival after recurrence (median, 14.2 vs. 6.8 months; $P=0.01$ ). In multivariate analyses, high serum a-fetoprotein level, synchronous intrahepatic recurrence and distant metastasis at the time of recurrence, and BSC were independently associated with poorer survival after recurrence. Sorafenib treatment was associated with better survival after recurrence as compared with BSC (hazard ratio, 0.25; 95\% confidence interval, 0.100.62; $P=0.002$ ). In addition, sorafenib group showed tolerable toxicity in the posttransplant setting. Sorafenib seems to be beneficial in patients with post-transplant HCC recurrence.

\section{INTRODUCTION}

Liver transplantation (LT) is the most effective therapy in carefully selected patients with hepatocellular carcinoma (HCC) [1]. Patients within the Milan criteria (MC) have shown 5-year recurrence-free survival and overall survival rates of $83 \%$ and $75 \%$, respectively [2]. However, post-transplant HCC recurrence is reported up to $8-20 \%$ of cases in spite of stringent selection of transplant candidates [1, 3-10]. The majority of patients with HCC recurrence after LT have systemic tumor spreading not amenable to resection or locoregional therapies $[3,4,11]$.
Moreover, transplanted patients are on multiple drugs including immunosuppressive agents, most of them are known to promote tumor growth $[12,13]$. Therefore, patients with systemic tumor recurrence generally show a dismal prognosis with a median survival of less than one year $[5,14]$. Management of these patients is a challenging issue, however, there is no consensus treatment strategy regarding $\mathrm{HCC}$ recurrence not amenable to resection or locoregional therapies.

Sorafenib, a multi-tyrosine kinase inhibitor, is the first drug to demonstrate a significant improvement in the overall survival (OS) of patients with advanced HCC [15]. 
It might be considered in selected cases of HCC recurrence after LT, when systemic treatment is warranted. However, only a few retrospective, small sized studies are available regarding the efficacy of sorafenib in these settings. A recent small case-control study showed that sorafenib seems to be associated with better survival compared to best supportive care (BSC) in this setting [16]. In contrast, several studies reported that sorafenib seems to be poorly tolerated because of drug to drug interactions with immunosuppressive agents, and rarely effective [17, 18]. Currently, the efficacy and safety of sorafenib in this setting are controversial.

In this study, we aimed to evaluate whether sorafenib, compared to BSC, could increase survival in patients with HCC recurrence after LT not amenable to surgical resection or locoregional therapies.

\section{RESULTS}

\section{Baseline characteristics}

During the study period, 502 patients underwent LT for HCC, 70 of whom developed recurrent HCC. Twenty-five patients presented upfront with a disease not amenable to resection, ablation or locoregional treatments, while 45 received multiple treatments until development of untreatable progression (UP). Of the 45 patients, four patients were cured by resection or ablation and did not need any further treatment, and one patient was lost to follow-up. Of the 65 patients presented with UP, 45 patients treated by sorafenib and 20 patients receiving BSC constituted our study population (Figure 1).

The baseline characteristics of patients are described in Table 1. The median age at HCC recurrence after LT was 55 years (interquartile range [IQR], 49-62 years) and 55 $(84.6 \%)$ patients were males. Hepatitis B virus infection was the most common etiology of the underlying liver disease. Fifty-two patients $(80.0 \%)$ underwent living-donor LT (LDLT). Forty-nine patients (75.4\%) were beyond MC at pre-transplant staging, and micro vascular invasion was present in 35 cases $(53.8 \%)$ at explant pathology. The median time from LT to recurrence was 8.2 months (IQR, $3.2-12.3$ months). Recurrence was limited to the liver in 5 patients $(7.7 \%)$, was limited to extrahepatic lesion in 30 patients $(46.2 \%)$, and was both intrahepatic and extrahepatic in 30 patients $(46.2 \%)$ at the time of recurrence. Patients underwent resection or locoregional treatments (range, 0-8) until developing UP. The median time from LT to UP was 11.2 months (IQR, 4.4-20.0 months).

Clinical characteristics were similar across the treatment groups except immunosuppressive strategy. All patients in the sorafenib group received tacrolimus as main immunosuppressant, while 3 in the BSC group received cyclosporine. Calcineurin inhibitors were maintained in $60.0 \%$ of patients in the BSC group, while $93.3 \%$ of the sorafenib group switched to mammalian target-ofrapamycin (mTOR) inhibitors after HCC recurrence $(P<0.001)$.

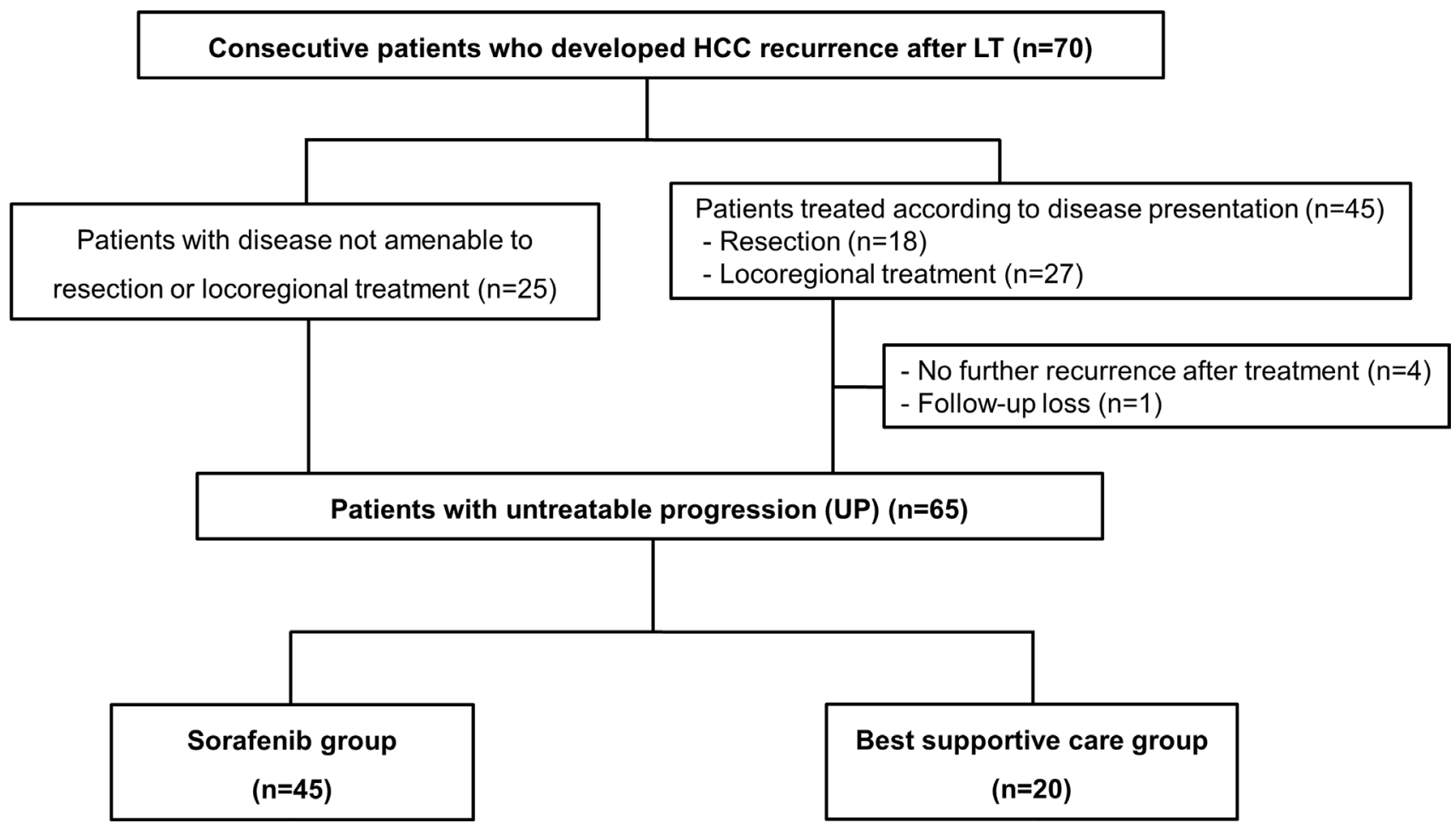

Figure 1: The diagram of patients flow. 
Table 1: Baseline characteristics of patients according to treatment group

\begin{tabular}{|c|c|c|c|}
\hline & $\begin{array}{c}\text { Sorafenib } \\
(n=45)\end{array}$ & $\begin{array}{c}\text { BSC } \\
(n=20)\end{array}$ & $\boldsymbol{P}$ \\
\hline Age at recurrence, years & $55(49-61)$ & $53(50-62)$ & 0.92 \\
\hline Male, $n(\%)$ & $41(91.1)$ & $14(70.0)$ & 0.06 \\
\hline Etiology of liver disease, $n(\%)$ & & & 1.00 \\
\hline HBV & $40(88.9)$ & $18(90.0)$ & \\
\hline HCV/other & $5(11.1)$ & $2(10.0)$ & \\
\hline Number of treatments before LT & & & 0.42 \\
\hline$<2$ & $22(48.9)$ & $7(35.0)$ & \\
\hline$\geq 2$ & $23(51.1)$ & $13(65.0)$ & \\
\hline Tumor stage (pre-LT), $n(\%)$ & & & 1.00 \\
\hline Within MC & $11(24.4)$ & $5(25.0)$ & \\
\hline Beyond MC & $34(75.6)$ & $15(75.0)$ & \\
\hline Type of LT, $n(\%)$ & & & 0.09 \\
\hline Living donor & $39(86.7)$ & $13(65.0)$ & \\
\hline Deceased donor & $6(13.3)$ & $7(35.0)$ & \\
\hline MVI (LT pathology) & $25(55.6)$ & $10(50.0)$ & 0.79 \\
\hline Main immunosuppressant before recurrence & & & 0.03 \\
\hline Cyclosporine & 0 & $3(15.0)$ & \\
\hline Tacrolimus & $45(100)$ & $17(85.0)$ & \\
\hline mTOR inhibitor use & $42(93.3)$ & $8(40.0)$ & $<0.001$ \\
\hline Episode of acute rejection, $n(\%)$ & $8(17.8)$ & $3(15.0)$ & 0.92 \\
\hline Time-to-recurrence, months & $6.5(2.8-11.7)$ & $11.7(6.1-14.6)$ & 0.18 \\
\hline Initial patterns of recurrence, $n(\%)$ & & & 0.77 \\
\hline Extrahepatic & $20(44.4)$ & $10(50.0)$ & \\
\hline Intrahepatic & $3(6.7)$ & $2(10.0)$ & \\
\hline Both & $22(48.9)$ & $8(40.0)$ & \\
\hline $\mathrm{AFP}$ at recurrence & $31.1(3.7-424.1)$ & $163.3(7.8-3376.5)$ & 0.27 \\
\hline PIVKA-II at recurrence & $110(39-777)$ & $131(40-1776)$ & 0.78 \\
\hline MELD score at recurrence & $7.4(6.4-10.0)$ & $7.9(6.6-10.5)$ & 0.91 \\
\hline Initial treatment at recurrence, $n(\%)$ & & & 0.65 \\
\hline Resection & $11(24.5)$ & $6(30.0)$ & \\
\hline Locoregional treatment & $15(33.3)$ & $8(40.0)$ & \\
\hline Sorafenib/BSC & $19(42.2)$ & $6(30.0)$ & \\
\hline Number of treatments after recurrence until UP & & & 0.79 \\
\hline$<2$ & $30(66.7)$ & $14(70.0)$ & \\
\hline$\geq 2$ & $15(33.3)$ & $6(30.0)$ & \\
\hline Time-to-UP, months & $7.0(3.2-12.3)$ & $3.7(1.5-8.1)$ & 0.49 \\
\hline
\end{tabular}

Data are median (interquartile range) or number (\%), unless otherwise indicated.

Abbreviations: AFP: $\alpha$-fetoprotein; BSC: best supportive care; HBV: hepatitis B virus; HCV: hepatitis C virus; LT: liver transplantation; MC: Milan criteria; MELD: Model for End-Stage Liver Disease; mTOR: mammalian target-of-rapamycin; MVI: microvascular invasion; PIVKA-II: prothrombin in vitamin K absence-II; UP: untreatable progression. 


\section{Survival analysis}

During the median follow-up period of 12.1 months (IQR, 5.7-20.9 months) after HCC recurrence, 57 out of 65 patients died. The median survival after recurrence and median survival after UP were 14.2 months $(95 \%$ confidence interval [CI], 9.6-18.8) and 9.4 months $(95 \%$ CI, 6.6-12.2) in the sorafenib group, while 6.8 (95\% CI, $1.7-16.7)$ and $3.2(95 \%$ CI, 2.8-3.6) months in the BSC group, respectively (Figure 2). Treatment with sorafenib conferred a survival advantage as compared with BSC both for survival after recurrence (hazard ratio [HR], $0.59 ; 95 \% \mathrm{CI}, 0.28-0.89 ; P=0.02)$ and survival after UP (HR, 0.17; 95\% CI, 0.09-0.34; $P<0.001$ ), respectively. In multivariate Cox regression analyses, high serum $\alpha$-fetoprotein (AFP) level, synchronous intrahepatic recurrence and distant metastasis at the time of recurrence, and receiving only BSC after UP were independently associated with poorer survival after recurrence (Table 2). Sorafenib treatment was independently associated with better survival after recurrence as compared with BSC (HR, $0.25 ; 95 \% \mathrm{CI}, 0.10-0.62 ; P=0.002$ ). In addition, sorafenib was also independently associated with better survival after UP (HR, 0.13; 95\% CI, 0.06-0.27; $P<$ $0.001)$.

In the subgroup analysis, sorafenib enhanced survival after recurrence compared with BSC both in patients who presented with UP at recurrence and those who received multiple treatments until development of UP $(P=0.005$ and 0.006 , respectively, Supplementary Tables 1 and 2). In addition, sorafenib treatment was associated with better prognosis in patients with high AFP levels ( $\geq 200 \mathrm{ng} / \mathrm{mL}, P=0.003$ ), patients developing early recurrence after LT $(<1$ year, $P<0.001)$, and patients who

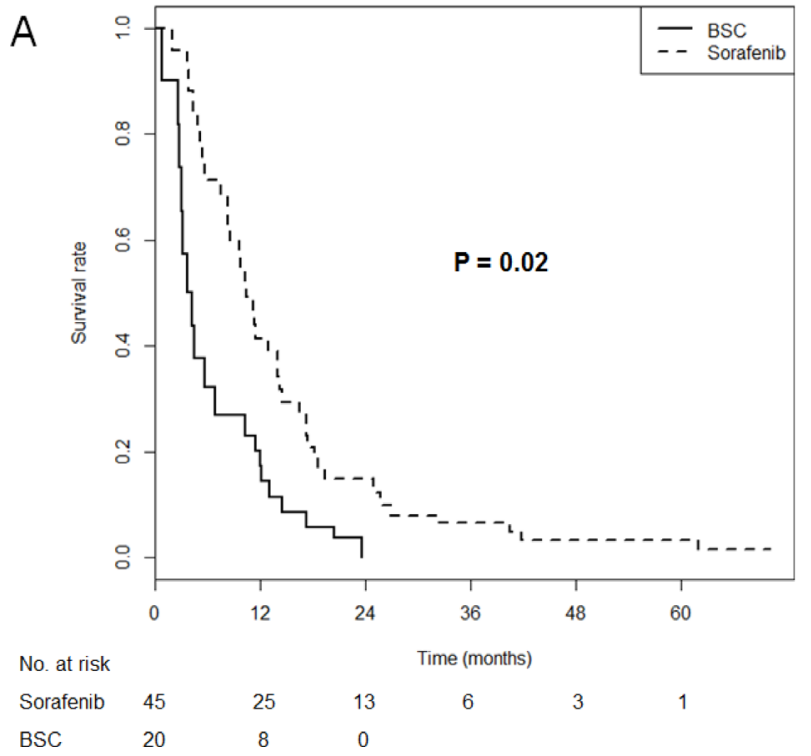

had recurrence limited to extrahepatic lesion at the time of recurrence $(P=0.04)$. Patients with low AFP levels $(<$ $200 \mathrm{ng} / \mathrm{mL}$ ), patients developing late recurrence after LT ( $\geq 1$ year), and patients who had intrahepatic recurrence with/without distant metastasis also showed similar trends, although the differences were not significant because of the small number of patients.

\section{Adverse events}

The adverse events during sorafenib were as follows: hand-foot syndrome was observed in 4 patients $(8.9 \%)$, diarrhea in $6(13.3 \%)$, alopecia in one $(2.2 \%)$, vomiting in one $(2.2 \%)$ and abnormality of liver function test in $2(4.4 \%)$, respectively. The adverse events were well controlled by a dose reduction and drug-related grade 4 or 5 toxicity did not occur. Sorafenib was withdrawn for progression of disease in 39 patients $(86.7 \%)$, one patient for liver function test abnormality, one patient for vomiting, two patients for diarrhea and one patient for hand-foot syndrome.

\section{DISCUSSION}

In this largest single-center report of sorafenib for recurrent HCC following LT, sorafenib treatment was associated with better post-recurrence survival as compared with BSC. The associations were independent of other well-known prognostic factors including serum AFP level and patterns of tumor recurrence. In addition, treatment with sorafenib in the post-transplant setting showed tolerable toxicity.

According to the previous studies regarding post-transplant HCC recurrence, median survival after

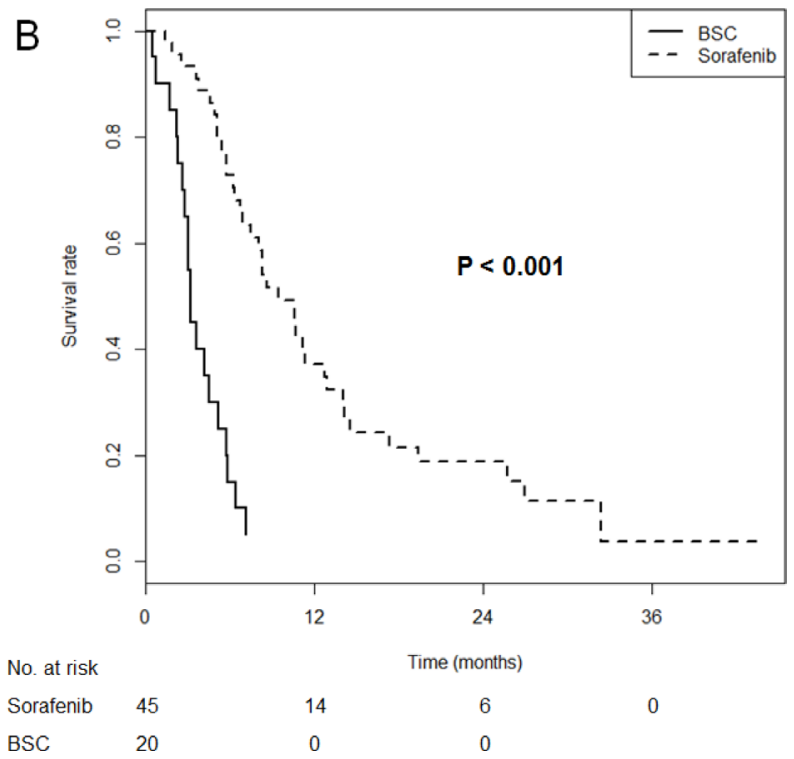

Figure 2: Kaplan-Meier estimates of survival after recurrence (A) and survival after untreatable progression (B) in patients with recurrent hepatocellular carcinoma after liver transplantation according to treatment group. Patients in the sorafenib group showed significantly longer survival after recurrence and survival after untreatable progression than patients in the best supportive care group. 
Table 2: Univariate and multivariate analyses of factors associated with survival after recurrence (corrected by time from recurrence to untreatable progression)

\begin{tabular}{|c|c|c|c|c|}
\hline & \multicolumn{2}{|c|}{ Univariate analysis } & \multicolumn{2}{|c|}{ Multivariate analysis } \\
\hline & HR $(95 \%$ CI) & $P$ & HR $(95 \%$ CI $)$ & $P$ \\
\hline $\begin{array}{l}\text { Tumor stage } \\
\text { (beyond } M C \text { vs. within } M C \text { ) }\end{array}$ & $0.85(0.45-1.60)$ & 0.62 & & \\
\hline Vascular invasion (histology) & $0.97(0.56-1.67)$ & 0.91 & & \\
\hline $\begin{array}{l}\text { Main immunosuppressant } \\
\text { (tacrolimus vs. cyclosporine) }\end{array}$ & $0.21(0.06-0.73)$ & 0.01 & $0.53(0.11-2.57)$ & 0.43 \\
\hline mTOR inhibitor use & $0.36(0.19-0.69)$ & 0.002 & $0.57(0.25-1.28)$ & 0.17 \\
\hline $\begin{array}{l}\text { AFP at recurrence } \\
(\geq 200 v s .<200)\end{array}$ & $2.49(1.39-4.45)$ & 0.002 & $1.99(1.01-3.90)$ & 0.04 \\
\hline MELD at recurrence & $1.03(0.99-1.08)$ & 0.14 & & \\
\hline $\begin{array}{l}\text { Time-to-recurrence }(\geq 1 \text { year } v s .<1 \\
\text { year) }\end{array}$ & $0.72(0.37-1.40)$ & 0.33 & & \\
\hline Initial patterns of recurrence & & 0.02 & & \\
\hline Extrahepatic & 1.00 & & 1.00 & \\
\hline Intrahepatic & $1.59(0.59-4.29)$ & & $1.00(0.31-3.21)$ & 0.99 \\
\hline Both & $2.40(1.29-4.47)$ & & $3.58(1.79-7.18)$ & 0.001 \\
\hline Initial treatment at recurrence & & 0.56 & & \\
\hline Resection & 1.00 & & & \\
\hline Locoregional treatment & $1.25(0.59-2.64)$ & & & \\
\hline Sorafenib/BSC & $0.94(0.44-2.01)$ & & & \\
\hline $\begin{array}{l}\text { Number of treatments after recurrence } \\
\text { until UP }\left(\geq 2 v_{s} .<2\right)\end{array}$ & $0.61(0.30-1.22)$ & 0.16 & & \\
\hline $\begin{array}{l}\text { Treatment after UP } \\
\text { (sorafenib vs. BSC) }\end{array}$ & $0.59(0.28-0.89)$ & 0.02 & $0.25(0.10-0.62)$ & 0.002 \\
\hline
\end{tabular}

Abbreviations: AFP: $\alpha$-fetoprotein; BSC: best supportive care; CI: confidence interval; HR: hazard ratio; MC: Milan criteria; MELD: Model for End-Stage Liver Disease; mTOR: mammalian target-of-rapamycin; UP: untreatable progression.

sorafenib treatment ranges between 17.8 and 38.5 months, suggesting an improvement of prognosis compared to BSC, albeit factors such as small sample size, the heterogeneity of the patients and treatment protocols may limit the conclusions [16, 17, 19]. Similarly, the non-adjusted median survival after recurrence and UP were more than doubled in the sorafenib group compared to BSC group in our study. Although sorafenib group were more often on mTOR inhibitors because they were treated in the most recent years, pre- and post-transplant characteristics associated with prognosis, such as MC in or out, microvascular invasion, or time-to recurrence were comparable between sorafenib and BSC group. In addition, treatment with mTOR inhibitors was not significantly associated with prognosis in the multivariate analysis. Furthermore, initial treatment at recurrence, number of treatment until UP, and time-to UP did not differ between two groups, suggesting consistent treatment policy regardless of different eras. These findings indicate that the survival difference between two groups may be mainly due to sorafenib treatment.

Meanwhile, the post-recurrence survival of sorafenib group in our study was relatively shorter than that of previous studies performed in Western transplant 
centers $[16,17,19,20]$. It may be resulted from different baseline characteristics of patients. First, more than half of the patients in our study had advanced HCC beyond the MC, and the median time to recurrence after LT was shorter compared with that of previous reports, suggesting more aggressive tumor biology of our cases [21]. Second, most patients $(83.3 \%)$ in our study received LDLT. It has been suggested that LDLT is associated with higher posttransplant HCC recurrence rate, compared to deceased donor LT because of release of growth factors that mediate rapid regeneration after implantation, shorter waiting time and fast track selection which might preclude the detection of aggressive tumor before LT [22-26]. Therefore, the poorer outcome of sorafenib group in our study compared to previous studies may be attributed to different baseline characteristics and unique features associated with LDLT. Nevertheless, the beneficial effect of sorafenib on survival was observed consistently even in the predominance of LDLT for HCC beyond the MC, supporting the potential role of sorafenib in post-LT HCC recurrence.

Dose reduction or withdrawn of sorafenib caused by adverse events occurred only in 5 patients, and the overall adverse events were acceptable with a comparable toxicity profile to the previous reports $[16,17,27]$. Our study shows that the tolerability of sorafenib for recurrent HCC after LT is comparable to the palliative setting of non-transplant HCC.

Combination of sorafenib and mTOR inhibitors has been an interesting issue because of the potential synergistic effects by targeting different major signaling pathways involved in hepatocarcinogenesis; $b$-Raf and mTOR/AKT [28]. Preclinical reports suggest that the combination therapy has additive efficacy compared with sorafenib alone [29, 30]. However, recent randomized phase II trial revealed that combination of sorafenib and everolimus did not improve OS compared with sorafenib alone in the first-line treatment of advanced HCC, although objective response favored the combination group [31]. Consistent with this, combination of sorafenib and mTOR inhibitors did not significantly improve prognosis compared to sorafenib alone in our patients with post-LT HCC recurrence, although the interpretation may be limited due to the small sample size. It would be better to test the combination strategy in target-enriched populations such as those with mTOR pathway activation.

Our study has several limitations. First, it is based on retrospective observational data. The different treatment eras related to the time of introducing sorafenib might act as a historical bias in comparing the sorafenib and BSC groups. However, both cohorts received similar treatment strategy over time as shown by similar time-to-recurrence, initial patterns and treatment at recurrence, number of treatments until UP, and time-to-UP. The different immunosuppression strategy between two groups might be a potential bias. However, previous reports suggesting a benefit of mTOR inhibitor are based on uncontrolled pilot studies, and recent multi-center randomized trial showed that sirolimus did not improve long-term progressionfree survival and OS compared with mTOR inhibitorfree immunosuppression in patients undergoing LT for HCC [32]. Therefore, the benefit of mTOR inhibitor in post-LT HCC is still not clear and more data are awaited. Second, although this study is the largest single-center report of sorafenib for recurrent HCC following LT to our knowledge, it is based on a relatively small sample size. Because of the low incidence of post-LT HCC recurrence, multi-center, prospective cohort studies are needed to investigate this issue more in depth.

Post-transplant $\mathrm{HCC}$ recurrence rates may be increased gradually due to the expansion of LT in HCC. Therefore, refinement of treatment strategy regarding HCC recurrence after LT is highly relevant in clinical practice. Our data suggest the intriguing possibility of sorafenib in patients with post-transplant HCC recurrence. Furthermore, sorafenib seems to be well tolerated in posttransplant setting. Further larger, prospective studies performed in real-life cohort are warranted to validate the present results.

\section{MATERIALS AND METHODS}

\section{Patients}

This retrospective cohort study included patients who were diagnosed with recurrent HCC following LT between October 2000 and May 2015 at Seoul National University Hospital (Seoul, Korea). Patients were divided into two groups according to treatment regimens after development of HCC not amenable to resection or locoregional treatment (untreatable progression [UP]) [16]. Patients treated by sorafenib after presenting with UP were classified as the sorafenib group, and those received only BSC including palliative radiotherapy to extrahepatic metastasis were classified as the control group.

The present study conformed to the ethical guidelines of the World Medical Association Declaration of Helsinki, and was approved by the Institutional Review Board of the Seoul National University Hospital. Documentation of informed consent was waived by the Institutional Review Boards because of the anonymous evaluation of data.

\section{Treatment of recurrence and outcomes}

After LT, all patients were monitored with dynamic computed tomography $(\mathrm{CT})$ scans or magnetic resonance imaging (MRI) every 2-4 months for the first 2 years and every 3-6 months thereafter. HCC recurrence was either confirmed by histology or diagnosed according to the noninvasive criteria of the American Association for the Study of Liver Disease [33]. 
Treatment of HCC recurrence was discussed and decided at multidisciplinary team meeting. Treatment strategy was carefully aimed, whenever possible, at complete surgical removal of recurrence. Radiofrequency ablation (RFA) was performed in patients with up to three intrahepatic recurrences $(\leq 3 \mathrm{~cm}$ in size) for which resection was not feasible. Transarterial chemoembolization was considered in patients with $(i)$ multi-nodular HCCs (more than three, $>3 \mathrm{~cm}$ in size); or (ii) risky or inaccessible lesions for RFA (i.e., hepatic dome or perivascular lesions). When tumor was deemed not anymore eligible to resection or locoregional therapies according to these criteria, patients received systemic chemotherapy or BSC until 2007, and received sorafenib based treatment or BSC thereafter. Sorafenib was initiated at a dosage of $400 \mathrm{mg}$ twice daily. In case of adverse events, the dose was tapered to $400 \mathrm{mg} /$ day and eventually to $400 \mathrm{mg}$ every other day, according to severity and persistence of symptoms. Sorafenib was withdrawn in case of serious adverse events or radiological tumor progression according to Response Evaluation Criteria in Solid Tumors (RECIST) 1.1 criteria.

The primary study objective was evaluation of the efficacy of sorafenib in patients with no otherwise treatable HCC recurrence after LT compared to BSC, according to survival time. Survival time was analyzed in two ways: (i) as the interval between tumor recurrence and death (survival after recurrence); (ii) as the interval between UP and death (survival after UP).

A toxicity profile was also evaluated in those patients according to the National Cancer Institute Common Terminology Criteria for Adverse Events version 4.0.

\section{Statistical analyses}

The Mann-Whitney $U$-test and Kruskal-Wallis test were used to analyze differences between the groups. The $\chi^{2}$ test or Fisher's exact test was used for categorical data. The cumulative rate of survival was calculated using the Kaplan-Meier method and the log-rank test was performed to compare the differences between the groups. Cox proportional hazards models were used to assess the influence of the clinical variables outcome. Considering that the investigated patients were selected as having UP, we used a left-truncated Cox proportional hazard regression model for the analysis of survival after recurrence to account for the interval between post-transplant HCC recurrence and assessment of UP (median, 11 months). Differences at $P<0.05$ were considered statistically significant. The statistical analyses were performed using SPSS for Windows, version 22.0 (SPSS Inc., Chicago, IL, USA) and R language ver. 3.2.0 (R Foundation for Statistical Computing, Vienna, Austria).

\section{Abbreviations}

AFP: a-fetoprotein; BSC: best supportive care; $\mathrm{CI}$ : confidence interval; HBV: hepatitis B virus; HCC: hepatocellar carcinoma; HCV: hepatitis C virus; HR: hazard ratio; IQR: interquartile range; LT: liver transplantation; LDLT: living-donor LT; MC: Milan criteria; MELD: Model for End-Stage Liver Disease; mTOR: mammalian target-of-rapamycin; MVI: microvascular invasion; OS: overall survival; PIVKA-II: prothrombin in vitamin K absence-II; RFA: radiofrequency ablation; UP: untreatable progression.

\section{Author contributions}

The study was designed by Cho EJ. Kang SH, Cho H, Nam JY, Chang Y, Cho YY were responsible for data collection. Kang $\mathrm{SH}$, Cho $\mathrm{H}$ performed the data and statistical analysis. Cho EJ, Lee J-H, Yu SJ, Kim YJ, Yi N-J, Lee K-W, Suh K-S and Yoon J-H supervised data collection, management and study implementation. All authors participated in data analysis and the preparation of the manuscript. All authors contributed according to the guidelines of the International Committee of Medical Journal Editors requested criteria for authorship and approved the final manuscript.

\section{CONFLICTS OF INTEREST}

The authors declare no conflicts of interest.

\section{FUNDING}

This work was supported by the Seoul National University Hospital Research Fund (Grant no. 30-20160190) and by the Liver Research Foundation of Korea, as part of Bio Future Strategies Research Project.

\section{REFERENCES}

1. Yao FY, Ferrell L, Bass NM, Watson JJ, Bacchetti P, Venook A, Ascher NL, Roberts JP. Liver transplantation for hepatocellular carcinoma: expansion of the tumor size limits does not adversely impact survival. Hepatology. 2001; 33:1394-403. https://doi.org/10.1053/jhep.2001.24563.

2. Mazzaferro V, Regalia E, Doci R, Andreola S, Pulvirenti A, Bozzetti F, Montalto F, Ammatuna M, Morabito A, Gennari L. Liver transplantation for the treatment of small hepatocellular carcinomas in patients with cirrhosis. $\mathrm{N}$ Engl J Med. 1996; 334:693-9. https://doi.org/10.1056/ NEJM199603143341104. 
3. Clavien PA, Lesurtel M, Bossuyt PM, Gores GJ, Langer B, Perrier A, OLT for HCC Consensus Group. Recommendations for liver transplantation for hepatocellular carcinoma: an international consensus conference report. Lancet Oncol. 2012; 13:e11-22. https://doi. org/10.1016/S1470-2045(11)70175-9.

4. Hollebecque A, Decaens T, Boleslawski E, Mathurin P, Duvoux C, Pruvot FR, Dharancy S. Natural history and therapeutic management of recurrent hepatocellular carcinoma after liver transplantation. Gastroenterol Clin Biol. 2009; 33:361-9. https://doi.org/10.1016/j. gcb.2009.02.036.

5. Davis E, Wiesner R, Valdecasas J, Kita Y, Rossi M, Schwartz M. Treatment of recurrent hepatocellular carcinoma after liver transplantation. Liver Transpl. 2011; 17 Suppl 2: S162-6. https://doi.org/10.1002/1t.22361.

6. Cescon M, Ravaioli M, Grazi GL, Ercolani G, Cucchetti A, Bertuzzo V, Vetrone G, Del Gaudio M, Vivarelli M, D'Errico-Grigioni A, Dazzi A, Di Gioia P, Lauro A, et al. Prognostic factors for tumor recurrence after a 12-year, single-center experience of liver transplantations in patients with hepatocellular carcinoma. J Transplant. 2010; 2010. https://doi.org/10.1155/2010/904152.

7. Kornberg A, Kupper B, Tannapfel A, Katenkamp K, Thrum K, Habrecht O, Wilberg J. Long-term survival after recurrent hepatocellular carcinoma in liver transplant patients: clinical patterns and outcome variables. Eur J Surg Oncol. 2010; 36:275-80. https://doi.org/10.1016/j. ejso.2009.10.001.

8. European Association for the Study of the Liver. EASL Clinical Practice Guidelines: Liver transplantation. J Hepatol. 2016; 64:433-85. https://doi.org/10.1016/j. jhep.2015.10.006.

9. Lee HW, Suh KS. Liver transplantation for advanced hepatocellular carcinoma. Clin Mol Hepatol. 2016; 22:30918. https://doi.org/10.3350/cmh.2016.0042.

10. Wang P, Li H, Shi B, Que W, Wang C, Fan J, Peng Z, Zhong L. Prognostic factors in patients with recurrent hepatocellular carcinoma treated with salvage liver transplantation: a single-center study. Oncotarget. 2016; 7:35071-83. https://doi.org/10.18632/oncotarget.9040.

11. de'Angelis N, Landi F, Carra MC, Azoulay D. Managements of recurrent hepatocellular carcinoma after liver transplantation: A systematic review. World J Gastroenterol. 2015; 21:11185-98. https://doi.org/10.3748/ wjg.v21.i39.11185.

12. Sheiner PA, Magliocca JF, Bodian CA, Kim-Schluger L, Altaca G, Guarrera JV, Emre S, Fishbein TM, Guy SR, Schwartz ME, Miller CM. Long-term medical complications in patients surviving $>$ or $=5$ years after liver transplant. Transplantation. 2000; 69:781-9.

13. Lee JY, Kim YH, Yi NJ, Kim HS, Lee HS, Lee BK, Kim H, Choi YR, Hong G, Lee KW, Suh KS. Impact of immunosuppressant therapy on early recurrence of hepatocellular carcinoma after liver transplantation. Clin
Mol Hepatol. 2014; 20:192-203. https://doi.org/10.3350/ cmh.2014.20.2.192.

14. Roayaie S, Schwartz JD, Sung MW, Emre SH, Miller CM, Gondolesi GE, Krieger NR, Schwartz ME. Recurrence of hepatocellular carcinoma after liver transplant: patterns and prognosis. Liver Transpl. 2004; 10:534-40. https://doi. org/10.1002/lt.20128.

15. Llovet JM, Ricci S, Mazzaferro V, Hilgard P, Gane E, Blanc JF, de Oliveira AC, Santoro A, Raoul JL, Forner A, Schwartz M, Porta C, Zeuzem S, et al. Sorafenib in advanced hepatocellular carcinoma. N Engl J Med. 2008; 359:378-90. https://doi.org/10.1056/NEJMoa0708857.

16. Sposito C, Mariani L, Germini A, Flores Reyes M, Bongini M, Grossi G, Bhoori S, Mazzaferro V. Comparative efficacy of sorafenib versus best supportive care in recurrent hepatocellular carcinoma after liver transplantation: a case-control study. J Hepatol. 2013; 59:59-66. https://doi. org/10.1016/j.jhep.2013.02.026.

17. Weinmann A, Niederle IM, Koch S, Hoppe-Lotichius M, Heise M, Duber C, Schuchmann M, Otto G, Galle PR, Worns MA. Sorafenib for recurrence of hepatocellular carcinoma after liver transplantation. Dig Liver Dis. 2012; 44:432-7. https://doi.org/10.1016/j.dld.2011.12.009.

18. Zavaglia C, Airoldi A, Mancuso A, Vangeli M, Vigano R, Cordone G, Gentiluomo M, Belli LS. Adverse events affect sorafenib efficacy in patients with recurrent hepatocellular carcinoma after liver transplantation: experience at a single center and review of the literature. Eur J Gastroenterol Hepatol. 2013; 25:180-6. https://doi.org/10.1097/ MEG.0b013e328359e550.

19. Gomez-Martin C, Bustamante J, Castroagudin JF, Salcedo M, Garralda E, Testillano M, Herrero I, Matilla A, Sangro B. Efficacy and safety of sorafenib in combination with mammalian target of rapamycin inhibitors for recurrent hepatocellular carcinoma after liver transplantation. Liver Transpl. 2012; 18:45-52. https://doi.org/10.1002/lt.22434.

20. de'Angelis N, Landi F, Nencioni M, Palen A, Lahat E, Salloum C, Compagnon P, Lim C, Costentin C, Calderaro J, Luciani A, Feray C, Azoulay D. Role of Sorafenib in Patients With Recurrent Hepatocellular Carcinoma After Liver Transplantation. Prog Transplant. 2016; 26:348-55. https://doi.org/10.1177/1526924816664083.

21. Toso C, Cader S, Mentha-Dugerdil A, Meeberg G, Majno P, Morard I, Giostra E, Berney T, Morel P, Mentha G, Kneteman NM. Factors predicting survival after post-transplant hepatocellular carcinoma recurrence. J Hepatobiliary Pancreat Sci. 2013; 20:342-7. https:/doi. org/10.1007/s00534-012-0528-4.

22. Park MS, Lee KW, Suh SW, You T, Choi Y, Kim H, Hong G, Yi NJ, Kwon CH, Joh JW, Lee SK, Suh KS. Livingdonor liver transplantation associated with higher incidence of hepatocellular carcinoma recurrence than deceased-donor liver transplantation. Transplantation. 2014; 97:71-7. https://doi.org/10.1097/TP.0b013e3182a68953. 
23. Grant RC, Sandhu L, Dixon PR, Greig PD, Grant DR, McGilvray ID. Living vs. deceased donor liver transplantation for hepatocellular carcinoma: a systematic review and meta-analysis. Clin Transplant. 2013; 27:140-7. https://doi.org/10.1111/ctr.12031.

24. Vakili K, Pomposelli JJ, Cheah YL, Akoad M, Lewis WD, Khettry U, Gordon F, Khwaja K, Jenkins R, Pomfret EA. Living donor liver transplantation for hepatocellular carcinoma: Increased recurrence but improved survival. Liver Transpl. 2009; 15:1861-6. https://doi.org/10.1002/ 1t. 21940

25. Man K, Fan ST, Lo CM, Liu CL, Fung PC, Liang TB, Lee TK, Tsui SH, Ng IO, Zhang ZW, Wong J. Graft injury in relation to graft size in right lobe live donor liver transplantation: a study of hepatic sinusoidal injury in correlation with portal hemodynamics and intragraft gene expression. Ann Surg. 2003; 237:256-64. https://doi. org/10.1097/01.SLA.0000048976.11824.67.

26. Kulik L, Abecassis M. Living donor liver transplantation for hepatocellular carcinoma. Gastroenterology. 2004; 127:S277-82.

27. Alsina AE, Makris A, Nenos V, Sucre E, Arrobas J, Franco E, Kemmer N. Can sorafenib increase survival for recurrent hepatocellular carcinoma after liver transplantation? A pilot study. Am Surg. 2014; 80:680-4.

28. Bhoori S, Toffanin S, Sposito C, Germini A, Pellegrinelli A, Lampis A, Mazzaferro V. Personalized molecular targeted therapy in advanced, recurrent hepatocellular carcinoma after liver transplantation: a proof of principle. J Hepatol. 2010; 52:771-5. https://doi.org/10.1016/j.jhep.2010.01.025.
29. Wang Z, Zhou J, Fan J, Qiu SJ, Yu Y, Huang XW, Tang ZY. Effect of rapamycin alone and in combination with sorafenib in an orthotopic model of human hepatocellular carcinoma. Clin Cancer Res. 2008; 14:5124-30. https://doi. org/10.1158/1078-0432.CCR-07-4774.

30. Piguet AC, Saar B, Hlushchuk R, St-Pierre MV, McSheehy PM, Radojevic V, Afthinos M, Terracciano L, Djonov V, Dufour JF. Everolimus augments the effects of sorafenib in a syngeneic orthotopic model of hepatocellular carcinoma. Mol Cancer Ther. 2011; 10:1007-17. https:// doi.org/10.1158/1535-7163.MCT-10-0666.

31. Koeberle D, Dufour JF, Demeter G, Li Q, Ribi K, Samaras P, Saletti P, Roth AD, Horber D, Buehlmann M, Wagner AD, Montemurro M, Lakatos G, et al. Sorafenib with or without everolimus in patients with advanced hepatocellular carcinoma (HCC): a randomized multicenter, multinational phase II trial (SAKK 77/08 and SASL 29). Ann Oncol. 2016; 27:856-61. https://doi.org/10.1093/annonc/mdw054.

32. Geissler EK, Schnitzbauer AA, Zulke C, Lamby PE, Proneth A, Duvoux C, Burra P, Jauch KW, Rentsch M, Ganten TM, Schmidt J, Settmacher U, Heise M, et al. Sirolimus Use in Liver Transplant Recipients With Hepatocellular Carcinoma: A Randomized, Multicenter, Open-Label Phase 3 Trial. Transplantation. 2016; 100:116-25. https://doi. org/10.1097/TP.0000000000000965.

33. Bruix J, Sherman M, American Association for the Study of Liver Diseases. Management of hepatocellular carcinoma: an update. Hepatology. 2011; 53:1020-2. https://doi. org/10.1002/hep.24199. 